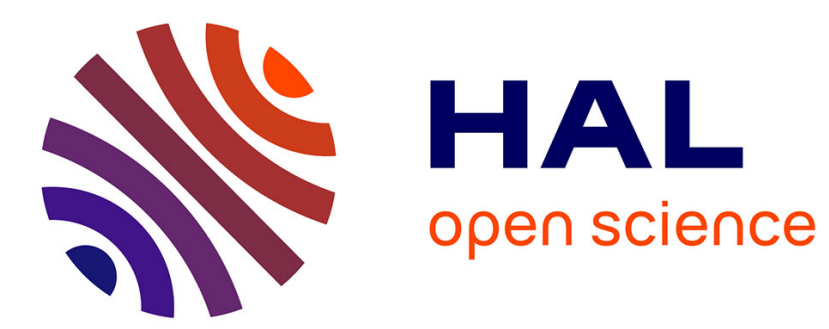

\title{
Ionic contrast terahertz time resolved imaging of frog auricular heart muscle electrical activity
} Jean-Baptiste Masson, Martin-Pierre Sauviat, Guilhem Gallot

\section{To cite this version:}

Jean-Baptiste Masson, Martin-Pierre Sauviat, Guilhem Gallot. Ionic contrast terahertz time resolved imaging of frog auricular heart muscle electrical activity. Applied Physics Letters, 2006, 89 (15), pp.153904. 10.1063/1.2360931 . hal-00824482

\section{HAL Id: hal-00824482}

https://hal-polytechnique.archives-ouvertes.fr/hal-00824482

Submitted on 1 Oct 2013

HAL is a multi-disciplinary open access archive for the deposit and dissemination of scientific research documents, whether they are published or not. The documents may come from teaching and research institutions in France or abroad, or from public or private research centers.
L'archive ouverte pluridisciplinaire HAL, est destinée au dépôt et à la diffusion de documents scientifiques de niveau recherche, publiés ou non, émanant des établissements d'enseignement et de recherche français ou étrangers, des laboratoires publics ou privés. 


\section{AIP Appied Physics \\ Letters}

\section{Ionic contrast terahertz time resolved imaging of frog auricular heart muscle electrical activity}

Jean-Baptiste Masson, Martin-Pierre Sauviat, and Guilhem Gallot

Citation: Appl. Phys. Lett. 89, 153904 (2006); doi: 10.1063/1.2360931

View online: http://dx.doi.org/10.1063/1.2360931

View Table of Contents: http://apl.aip.org/resource/1/APPLAB/v89/i15

Published by the AIP Publishing LLC.

\section{Additional information on Appl. Phys. Lett.}

Journal Homepage: http://apl.aip.org/

Journal Information: http://apl.aip.org/about/about_the_journal

Top downloads: http://apl.aip.org/features/most_downloaded

Information for Authors: http://apl.aip.org/authors

\section{ADVERTISEMENT}

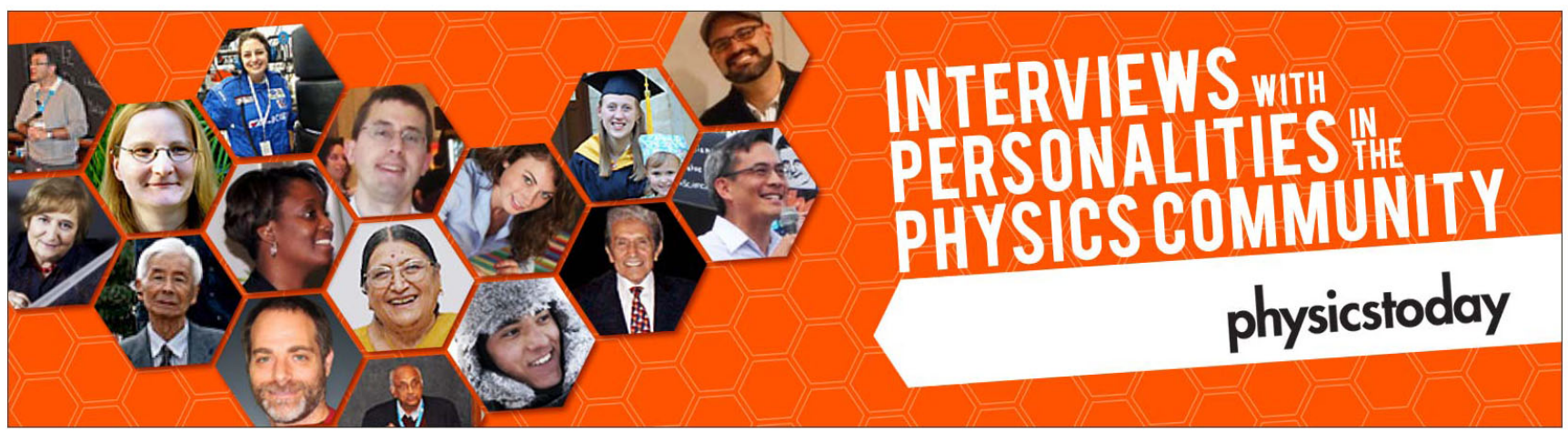




\title{
lonic contrast terahertz time resolved imaging of frog auricular heart muscle electrical activity
}

\author{
Jean-Baptiste Masson, Martin-Pierre Sauviat, and Guilhem Gallot ${ }^{a)}$ \\ Laboratoire d'Optique et Biosciences, École Polytechnique, CNRS, INSERM, 91128 Palaiseau, France
}

(Received 3 July 2006; accepted 30 August 2006; published online 12 October 2006)

The authors demonstrate the direct, noninvasive and time resolved imaging of functional frog auricular fibers by ionic contrast terahertz (ICT) near field microscopy. This technique provides quantitative, time-dependent measurement of ionic flow during auricular muscle electrical activity, and opens the way of direct noninvasive imaging of cardiac activity under stimulation. ICT microscopy technique was associated with full three-dimensional simulation enabling to measure precisely the fiber sizes. This technique coupled to waveguide technology should provide the grounds to development of advanced in vivo ion flux measurement in mammalian hearts, allowing the prediction of heart attack from change in $\mathrm{K}^{+}$fluxes. (C) 2006 American Institute of Physics.

[DOI: $10.1063 / 1.2360931]$

Recent development in terahertz technology and in terahertz imaging offer new possibilities in biology. Among the involved advantages and by contrast to $x$-ray imaging, the sample does not suffer from terahertz imaging, thanks to the low associated photon energy. We recently demonstrated ionic contrast terahertz (ICT) for neuron imaging, ion flux detection, and axonal water swelling using very sensitive absorption of terahertz radiation to biological ion concentration. ${ }^{1}$ Terahertz imaging has also been used for tissue investigations with diagnosis perspectives in dermatology and odontology. ${ }^{2-6}$ Finally recent developments in terahertz guiding through waveguides and metal wires offer the perspective of probing biological sample in situ. ${ }^{7}$

In this letter, we demonstrate the application of ICT near field imaging on living frog heart muscle dynamic electrical activity. We have recorded ionic fluxes of spontaneously beating, nonstimulated, and unstained auricular muscle with time resolution of $10 \mathrm{~ms}$ using the contrast in terahertz absorption of the relevant biological ions. We find that the main ionic activity occurs during the first $390 \pm 10 \mathrm{~ms}$ with a $1.49 \pm 0.01 \mathrm{~s}$ beating period. Extra systolic electrical response has also been observed.

In living cells and more specifically in cardiac muscles the most relevant ions are $\mathrm{Na}^{+}, \mathrm{K}^{+}$, and $\mathrm{Ca}^{++}$. Time domain spectroscopy allows us to record ionic terahertz absorption profiles of $\mathrm{NaCl}, \mathrm{CaCl}_{2}$, and $\mathrm{KCl}$ solutions. ${ }^{1}$ Broadband linearly polarized subpicosecond single cycle pulses of terahertz radiation are generated and coherently detected by illuminating photoconductive antennas with two synchronized femtosecond laser pulses. The samples are double de-ionized water with precise control of added quantities of $\mathrm{NaCl}$, $\mathrm{CaCl}_{2}$, and $\mathrm{KCl}$. The $100-\mu \mathrm{m}$-thick liquid sample is contained in a polyethylene cell with 5-mm-thick walls in order to avoid Fabry-Pérot effects during scan. The spectrum exhibits a progressive increase of absorption with respect to the frequency. The absorption results from the modification of the dielectric properties of the water solvent by the surrounding ions. The sequence of typical molar absorption $\left(\mathrm{mM}^{-1} \mathrm{~cm}^{-1}\right)$ at $1 \mathrm{THz}$ is $\mathrm{Ca}^{++}(4) \geqslant \mathrm{K}^{+}(3.5)>\mathrm{Na}^{+}(1){ }^{1}$

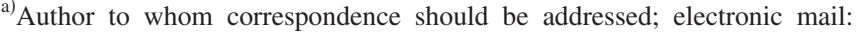
guilhem.gallot@polytechnique.fr
}

In order to measure the ions variations we have performed near field imaging with aperture. ${ }^{1}$ The terahertz radiation is focused by a hyperhemispherical Teflon lens onto a subwavelength-diameter hole, lying on a $10-\mu \mathrm{m}$-thick aluminum screen (see Fig. 1). The hole breaks the incident terahertz wave and reemits a polarized terahertz pulse with much higher spatial frequency. Furthermore, the electric field has a highly anisotropic spatial profile which is the cause of the higher spatial frequency. The size of the hole results from a compromise between spatial resolution required for the sample, radiation transmission, and signal-to-noise ratio. The frog auricular muscle is positioned closely behind the subwavelength hole and the transmitted terahertz radiation is focused by another hemispherical lens onto the photoconductive detector. During imaging, the delay between the two femtosecond pulses remains constant, and the amplitude of the transmitted beam is recorded.

The biological sample is prepared immediately before experimenting. The heart is removed from the frog chest, and

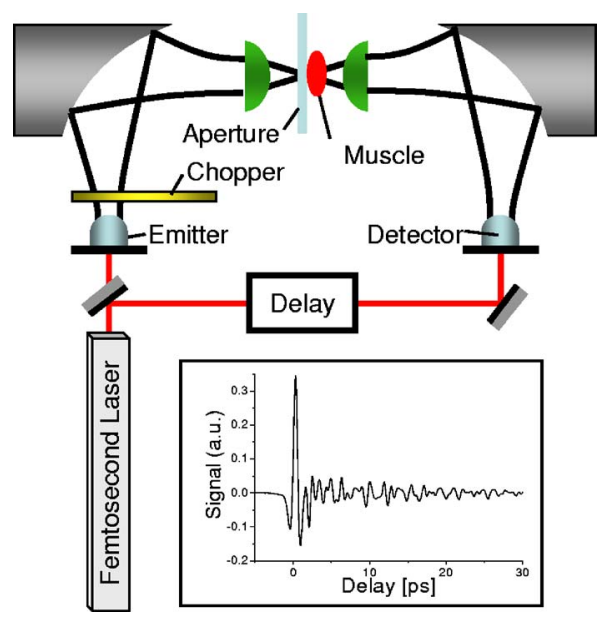

FIG. 1. (Color online) Setup for near-field terahertz microscopy. A femtosecond laser generates terahertz pulses, which propagate through free space. A chopper and lock-in device allow one to record the amplitude of the electric field. Terahertz radiation is focused onto a subwavelength hole by a hyperhemispherical Teflon lens. The frog muscle sample is put behind the hole, and the transmitted terahertz pulse is focused by another hemispherical lens to the detector. Measurements are done keeping the delay constant. 

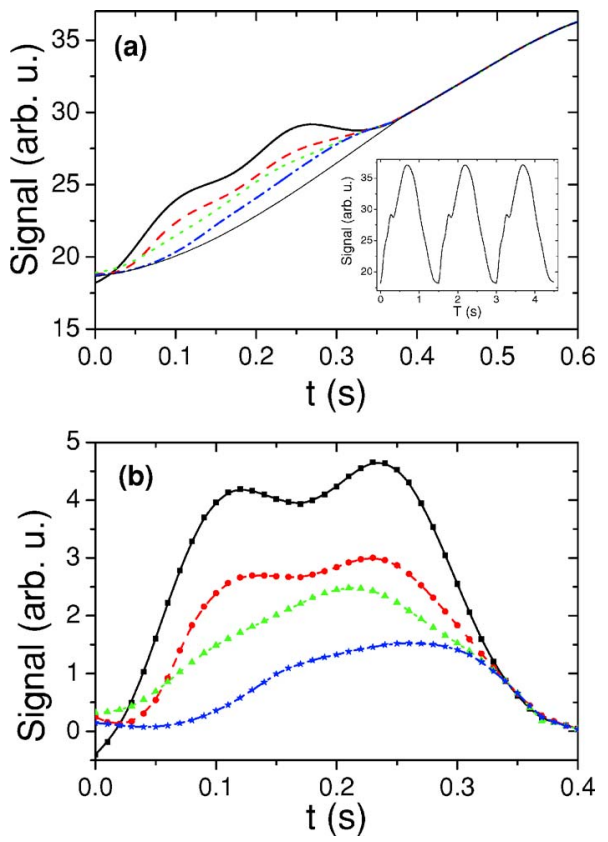

FIG. 2. (Color online) (a) Detail of the periodic terahertz amplitude signal recorded through a self-beating frog auricular heart muscle. Delay $t$ refers to the delay after the start of each beating. Time integration is $10 \mathrm{~ms}$, averaged over ten consecutive periods. Measurements are done after 5 min (thick solid black), $20 \mathrm{~min}$ (dashed red), $40 \mathrm{~min}$ (dotted green), and $50 \mathrm{~min}$ (dashed-dotted blue). The thin black solid line stands for the mechanical motion background. Inset shows three full mechanical oscillations. Delay $T$ refers to the total measurement time. (b) Some terahertz ion flux signatures (at $T=5,20,40$, and $50 \mathrm{~min}$ ) extracted by subtracting the reproducible mechanical motion of the muscle.

bathed in a physiological solution for few minutes. Then, a fine atrial trabeculae (100-200 $\mu \mathrm{m}$ in diameter and $1-2 \mathrm{~cm}$ length) is dissected from the auricule and strongly fixed using Vaseline seal $(100 \mu \mathrm{m})($ Ref. 8$)$ on a plate with an aperture in the middle. The fiber is constrained so that its only direction of motion is perpendicular to the plate, i.e., the direction of the terahertz beam. During the experiment, the fiber is spontaneously beating due to the self-evolution of the internal ion fluxes and develops an action potential (AP). The exceptional signal to noise ratio allows the recording with a $10 \mathrm{~ms}$ integration time required to resolve the signal evolution. An average of the signal over ten periods of beating reduces the noise level but does not affect the signal profile. A typical periodic signal is shown in Fig. 2(a). Because of the muscle contraction, the signal is the sum of this mechanical effect and of the variation of the ion flux. The fiber contraction mainly changes the thickness of the sample and then the absorption of the incident terahertz beam. The global motion is sinusoidal-like by the mechanical inertia of the muscle and the Vaseline environment. This motion is triggered by the self-evolution of the ion fluxes in the muscle. The self-beating signal has a period of $1.49 \pm 0.01 \mathrm{~ms}$ and the effect of ions appears at the beginning of the signal during about $400 \mathrm{~ms}$. In order to remove the inertial component of the recorded signal, the constant part was fitted by a sinus function and subtracted from all the curves. Some extracted signals are presented in Fig. 2(b) with respect to the delay $t$ after the start of the AP. The period of ion variation is found to be $0.390 \pm 0.01 \mathrm{~s}$. These signals decline with the duration $T$ of the experiment and are proportional to the ionic fluxes. They may correspond to the AP and are called AP signals. First, we observed a general decrease of the ion fluxes, as

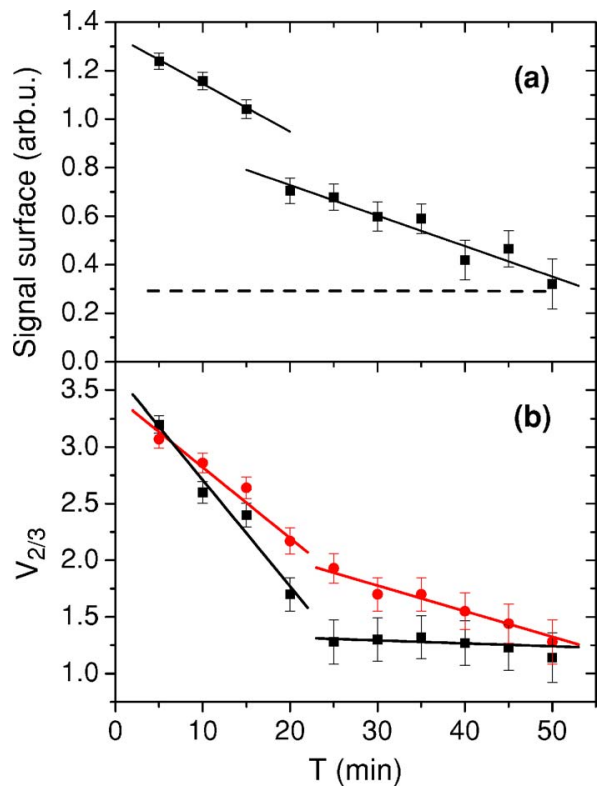

FIG. 3. (Color online) (a) Time evolution of the total surface of the action potential vs total time $T$. Solid lines are linear fits. The dotted line indicates when the frog auricular heart muscle stopped beating. (b) Time evolution of $V_{2 / 3}=V\left(t=2 / 3 t_{\max }\right)$, where $t_{\max }$ is the time at maximum signal in the rising (square, black) and decreasing (circle, red) fronts of the signal. Solid lines are linear fits.

shown in Fig. 3(a). The decrease of the signal implies two main steps. Between $T=0$ and 15 min the signal remained almost identical, and then a strong decrease appeared. Finally, after $T=50 \mathrm{~min}$, the heart stopped beating. The shape of the AP signal recorded is now analyzed more precisely, since it is related to the establishment of the ion fluxes through the membrane according to conventional electrophysiology. The rising phase of this AP signal originates from the depolarization of the membrane due to a $\mathrm{Na}^{+}$entry caused by the opening of the voltage-gated $\mathrm{Na}^{+}$channels. Since the molar absorptions of $\mathrm{K}^{+}$and $\mathrm{Ca}^{++}$are comparable, we cannot distinguish the $\mathrm{K}^{+}$and $\mathrm{Ca}^{++}$ion fluxes during the AP plateau. The slowing down of the signal which drops after $t=300 \mathrm{~ms}$ is due to the repolarization by $\mathrm{K}^{+}$fluxes through voltage-gated $\mathrm{K}^{+}$channels. It should be noted that the amplitude of the $\mathrm{K}^{+}$signal is amplified by a factor 3.5 with respect to the $\mathrm{Na}^{+}$signal. The first signal at $T=5 \mathrm{~min}$ [Fig. 2(a)] shows the initial polarization triggering the AP signal. Afterward, the baseline is shifted positively, showing that the fiber is depolarized. Quantitatively, the amplitude of the rising and decreasing phases of the AP signal are described by the amplitude $V_{2 / 3}=V\left(t=2 / 3 t_{\max }\right)$, where $t_{\max }$ is the time at maximum signal. The amplitudes $V_{2 / 3}$ are shown in Fig. 3(b). They exhibit different evolutions. In the rising phase, $V_{2 / 3}$ drops quickly in about $20 \mathrm{~min}$, then remains low and stable. $V_{2 / 3}$ might be similar to $V_{\max }$ (Ref. 8) which represents the onset of the $\mathrm{Na}^{+}$influx. Then, a decrease of $V_{2 / 3}$ implies a rapid decrease of the $\mathrm{Na}^{+}$fluxes. The decreasing phase shows continuous drop of $V_{2 / 3}$, associated with the repolarization by $\mathrm{K}^{+}$eflux.

After $T=50 \mathrm{~min}$, the fiber is bathed in a fresh physiological liquid and is mechanically stimulated. Following this procedure, modifications of the duration of the ionic flow occurred, and after a period of recovery, it preceded increases of the beating period. Typical results are depicted in Fig. 4. The duration of the AP signal increased by about 


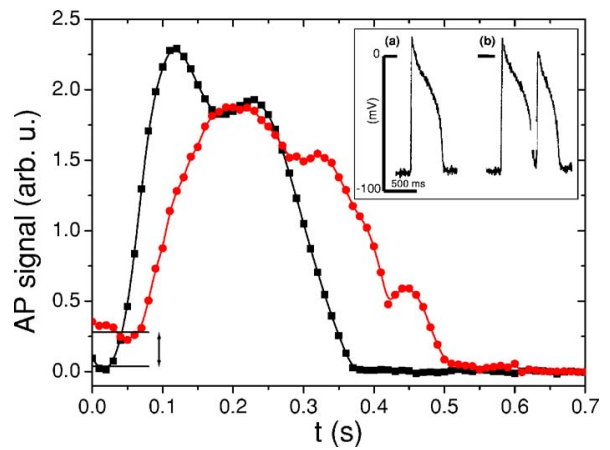

FIG. 4. (Color online) Comparison between AP signals of frog auricular fiber in the control physiological solution recorded after $T=5 \mathrm{~min}$ (square, black) and $T=60 \mathrm{~min}$ (circle, red). The inset presents the spontaneously beating frog auricle electrical activity recorded in the physiological solution using intracellular microelectrodes. (a) AP and (b) AP associated with a late arrhythmic response.

$50 \%$. The maximum of time widening of ion flow increased up to $610 \pm 10 \mathrm{~ms}$ and a second less intense AP component occurs at a delay $t$ of about $450 \mathrm{~ms}$ (Fig. 4). After this point, the muscle started an erratic arrhythmic behavior which corresponds to an extra systolic event. This arrhythmic event is similar to the one occurring in spontaneously beating fibers (inset of Fig. 4). It is correlated to an abnormal positive base line of the AP signal. These data are consistent with the AP duration and frequency of spontaneously beating frog atrial fibers, ${ }^{8}$ which action potential duration was ranging from 350 to $500 \mathrm{~ms}$ recorded using intracellular microelectrodes (inset of Fig. 4).

Finally, after the heart definitely stops beating, we performed imaging of the transverse section of one fiber. As in all ICT measurements, ${ }^{1}$ the delay remains constant and the amplitude of the signal is recorded versus the position of the fiber. The profile of the fiber originates from the difference of absorption between inside and outside the fiber. Then, the normalized curve is fitted with tabulated numerical simulations. The fiber diameter was found to be $175 \pm 1 \mu \mathrm{m}$.

In conclusion, we showed an application of the ICT imaging in a dynamic system. We have successfully monitored the ion flow in a frog auricular muscle with a time resolution of $10 \mathrm{~ms}$. We showed the direct time evolution of the ion flows during cardiac AP. These experiments open up new applications of terahertz technologies to biological systems both in imagery and time-resolved process. Furthermore, coupling the ICT imaging with terahertz guiding systems will offer new possibilities for in vivo research. This technique offers a promising alternative to conventional techniques, such as intracellular microelectrodes, patch clamp recording, fluorescence, and microscopy.

${ }^{1}$ J.-B. Masson, M.-P. Sauviat, J.-L. Martin, and G. Gallot, Proc. Natl. Acad. Sci. U.S.A. 103, 4808 (2006).

${ }^{2}$ A. J. Fitzgerald, E. Berry, N. N. Zinovev, G. C. Walker, M. A. Smith, and J. M. Chamberlain, Phys. Med. Biol. 47, R67 (2002).

${ }^{3}$ R. M. Woodward, B. E. Cole, V. P. Wallace, R. J. Pye, D. D. Arnone, E. H. Linfield, and M. Pepper, Phys. Med. Biol. 47, 3853 (2002).

${ }^{4}$ D. Crawley, C. Longbottom, V. P. Wallace, B. E. Cole, D. D. Arnone, and M. Pepper, J. Biomed. Opt. 8, 303 (2003).

${ }^{5}$ T. Löffler, T. Bauer, K. J. Siebert, H. G. Roskos, A. Fitzgerald, and S. Czasch, Opt. Express 9, 616 (2001).

${ }^{6}$ S. M. Kim, F. Hatami, J. S. Harris, A. W. Kurian, J. Ford, D. King, G. Scalari, M. Giovannini, N. Hoyler, J. Faist, and G. Harris, Appl. Phys. Lett. 88, 159303 (2006).

${ }^{7}$ K. Wang and D. M. Mittleman, Nature (London) 432, 376 (2004).

${ }^{8}$ M.-P. Sauviat, M. Marquais, and J.-P. Vernoux, Toxicon 40, 1155 (2002). 